\title{
Research Data Management in China: Can Librarians Bring a Paradigm Shift?
}

\author{
Isidore Komla Zotoo ${ }^{*}$, Guifeng Liu ${ }^{2}$, Zhangping Lu${ }^{1}$, Frank Kofi Essien ${ }^{1}$ \\ ${ }^{1}$ School of Management, Jiangsu University, Zhenjiang, China \\ ${ }^{2}$ Institute of Science and Technology Information, Jiangsu University, Zhenjiang, China \\ Email: *zotook@yahoo.com
}

How to cite this paper: Zotoo, I.K., Liu, G.F., Lu, Z.P. and Essien, F.K. (2022) Research Data Management in China: Can Librarians Bring a Paradigm Shift? Open Access Library Journal, 9: e8341.

https://doi.org/10.4236/oalib.1108341

Received: December 30, 2021

Accepted: February 11, 2022

Published: February 14, 2022

Copyright () 2022 by author(s) and Open Access Library Inc.

This work is licensed under the Creative Commons Attribution International License (CC BY 4.0).

http://creativecommons.org/licenses/by/4.0/

(c) (i) Open Access

\begin{abstract}
Research data management (RDM) practices in China are underdeveloped despite the release of RDM policy on $2^{\text {nd }}$ April 2018 and research to unearth these challenges cannot be overemphasized. The objective of this study is to investigate the relationship among critical stakeholders in RDM specifically from librarians' perspective to speed up the RDM agenda for maximum benefit. This study used Structural Equation Modeling (SEM) to study the relationship among critical stakeholders in RDM. The findings revealed that the relationships among different stakeholders are significantly positive, and that institutions mediate the positive effect of Librarian on researchers' work. The effect of government on librarians is not significant. This later finding may be largely due to the poor attitudes of government towards the librarians, however, there could be a positive mediating effect rather than direct. This means that the librarians could bring a paradigm shift in RDM. Librarians should take a leadership role in RDM and should be involved in decision making. This could be the way forward to change the status quo in RDM. This study contributes to the discourse by helping to strengthen the existing relationship and also to understand the role of librarians in RDM.
\end{abstract}

\section{Subject Areas}

Information Science, Library, Intelligence and Philology

\section{Keywords}

Research Data Management, Stakeholders, Librarians, Relationship, Stakeholders' Relationship

\section{Introduction}

There is increase in the research work. Today many researchers are faced with 
research data management need. In order to get quality result and safeguard the data, many countries have introduced research data management policies to streamline the process. Research Data Management (RDM) is a comprehensive set of activities for the organization, storage, access, and preservation of data [1]. These activities include services, tools, and infrastructure that support research data across its lifecycle [2]. These services are gathering, planning, RDM Informatics, research data citation, RDM training, storage access and impact with research support office. Many policies have been formulated for the effective management of research data with various stakeholders' involvement to do a good job. According to [3], in the USA, UK and Australia, data sharing, data management plan, access, and retention are critical requirements from funders as conditions to access research grants. These countries are benefiting as the implementation of the policies is visible in the academic institutions. The situation is not same in China despite the availability of national RDM policy.

Over the past decade, many studies have been conducted to assess the current level of RDM in China. According to [4] since research data management policy was adopted almost more than two years now ( $2^{\text {nd }}$ April 2018), only one university has a visible research data management policy, meanwhile the released is expected to pave way for institutions to implement their own institutional policy in line with national policy. Comparing these levels to same happening in Europe after a year China has performed very low [5]. The authors argue that it may be because there is existing infrastructure for data management dedicated for data intensive discipline. It was also found that libraries in China are less persuasive because they have no licensed librarians managing them and more especially because they are not involved in RDM policy, there is "wait and see attitudes" [6]. The unavailability of institutional research data management policies is a challenge because it is the implementation of such policies that will pave way for the full benefit of research data management to be realized. It is therefore important to understand the process leading to the formulation of such policies as the success of RDM depends on the interaction among key players such as the librarians, the researchers, government, institutions, and the funders or donors [7].

RDM has many stakeholders at all levels, such as journal publishers and funding agencies [8]. Others are institutions, librarians, government and researchers. Previous findings in [9] have shown that the stakeholders benefit more if they participate in policy formulations for a sustainable competitive advantage of the institutions in funded research. It was found that comparing motivation to satisfaction with the project outcome can give a valuable lesson for the success of RDM through partnership [10]. Opinions are divided among management of many institutions, whiles some see the relevance of participating in RDM, others remain adamant that investments into RDM are not competitive or worth worthy. The standpoint group also thinks that not all institutions need DMP [11]. While cost could be a challenge, it may not be the only reason that 
handicaps the implementation of RDM [5]. Previous research has found conflict and tension among these stakeholders in various institutions [12]. Despite the attempt to resolve this by providing division of role, it remains very doubtful. If this is not resolved, it can impede the success of RDM. A study in Whyte [13], librarians and research office showed commitment by coordinating and promoting the RDM policies. There is also some level of mixed stakeholders supervising the implementation and governance. Many of the studies have not investigated the direct relationship among the stakeholders. Close collaboration among all the stakeholders is required to initiate, promote, foster and strengthen collective learning and overcome new problems that may come up along with research activities. The diversity of stakeholders suggests careful management of these relationships along the data management lifecycle. There must exist a good communication and cooperation among these groups [14]. This relationship is deemed very important for a successful RDM. This lack of good interrelationship may be a factor impeding the urgency for sound RM practices as seen in other countries such as developed countries.

In making a case for librarians to be involved in $\mathrm{RDM}$, a number of scholars have argued that services in library in higher institutions are strategically positioned to offer a significant role in RDM [15] [16] [17]. This is because librarians have practical skills that could be of use in RDM [18]. These include advisory and training services. The result of study has shown that libraries of 20 best universities demonstrated enough commitment to provide services such as how to write RDMP, data preservation, publishing, managing personal and sensitive data [5]. They suggested that libraries need to take leading role in the management of the research data generated in academic institutions. In study conducted by [19], the result of studies conducted shows that librarians need innovative performance to remain relevant. The authors state that librarians are the frontline workers for the implementation of RDS. They also found that librarians feel they have knowledge for bid data management but needed in service training in order to remain on top of issues. Librarians share the role for building a strong RDM service.

Another study conducted by Faniel and Connaway [20] in which 36 academic librarians where sampled about the factors that influence RDM support and experience, the result revealed that (twenty five) $25 \%$ of the academic librarians state that there is negative perception about them by researchers. This is because libraries initiated the support late as result compiling researchers to start their own initiative to embrace the current trend. A survey of librarians and managers of (twenty two) 22 UK research librarians in Auckland [21] argue that libraries are already overburdened and therefore this will put more demand on their time. He believed that other existing service may suffer or be less prioritized. This is because infrastructure, funding which are key requirement for RDM are already suffering. The author sees their position not to be too clear. The author believed that their involvement cannot be automatic based on their previous knowledge but a whole set of knowledge is needed such as organizing of projects, thought 
leaders and key influencers, technologies, discourses, concepts and terminology and IT knowledge. It was stated that there is absence of explicit analytical acknowledgment in research data management policy [2]. These challenges need to be further investigated and addressed in order to better engage librarians in high levels of interaction with researchers while cooperating with other support service providers such as institutions, funders and government [22]. This evidence is also buttress in [23]. This very relationship and engagement need to be investigated in order to have a clear mindset and objectives. Extant literature did not test the relationship among key stakeholders. In the context with these challenges this study seeks to investigate the relationship among the stakeholders in research data management to unravel the cause of delayed in implementing research data management policies at the institutional level and to understand the kind of relationship that exist among them.

\section{Theory and Hypothesis Development}

The leading theory base of this study is that of stakeholders originated from [24] who define a stakeholder as 'any group or individual who can affect or is affected by the achievement of the organization's objectives' (p. 46). Stakeholder's theory argues that organizations' work affects other parties that are within and external to the institutions. Identifying such individuals or groups of people is vital to their success since they can negatively or positively affect organizational performance [25]. These stakeholders' requirements must be known and well understood for proper implementation RDM can be the way forward to better meet the challenges by investigating the relationship among them for adequate management. This theory was used in Wang and Huang [26] to understand how project performance and project success correlate. The author used the golden triangular approach that advanced that project should comprise golden triangular and key stakeholders to measure project success [27]. The stakeholders were made up project owner, construction supervisor, and construction contractor to form the triangle. It was found that, the engineer uses "relation" as a key indicator for project success among the stakeholders. Studies have shown that there are no criteria to evaluate project success as it has been used in many fields [28], including business, management, finance and accounting. The triangular approach was adopted and modified for this study to include funders, government (the project owner), Institution and librarians (project supervisors) and project contractor (researchers). This enables us to investigate these stakeholders to ascertain the relationship among multi-stakeholders within research project data management as in stakeholders influence theory Rowley [29] which accommodate multiple and interdependent stakeholders by incorporating their demands and to forecast how they will influence organisations' response to such multiple stakeholders. Based on the stakeholder's theory and the literature above, the following hypotheses are developed as shown in Figure 1:

H1 Funders positively impact researchers 


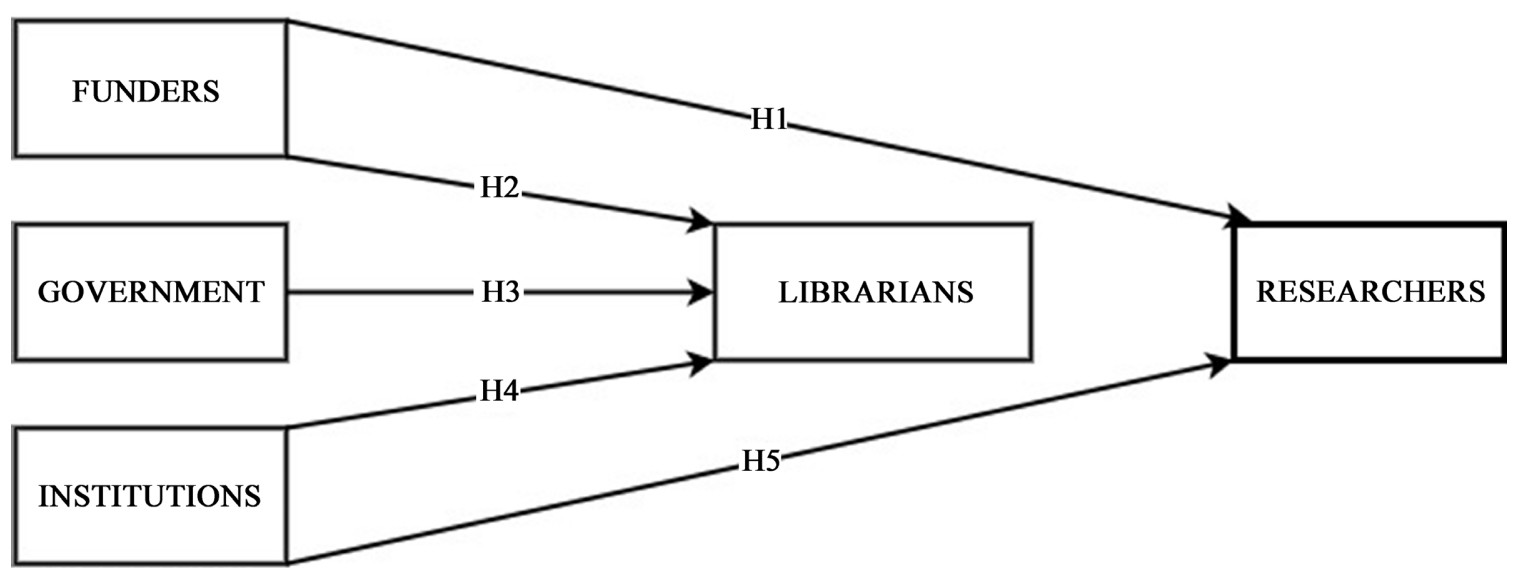

Figure 1. Conceptual framework [30].

H2 Funders positively impact librarian.

H3 Government positively impact librarians.

H4 Institutions positively impact librarians.

H5 Institutions have a positive impact on the work of researchers.

\section{Methodology}

The research approach used in this research is the inductive research where the study derives from previous concepts, approaches and theories in formulating the research hypothesis and objectives. The research employs an explanatory research design that seeks to discover the causal relationships between the research variables. The tool used in this analysis is the Structural Equation Modeling technique aided by SmartPLS3. The Structural Equation Model is a plethora of techniques comprises of component reliability test techniques, component validity test, common method bias techniques and path analysis technique measures. This model is a powerful model for assessing relationships between variables.

Data were collected through online survey with the link to questionnaire given to only librarians. After the data was collected, it was organized using Microsoft Excel spreadsheet and saved in the csv format for further processing and analysis using SmartPLS3 statistical software based on 200 questionnaires received from librarians in China. Many of the research works in information science are a theoretical [31] Ullah and Ameen [32] also confirm it. The study shows innovation by adopting a quantitative approach in explaining the research data management and stakeholders' relationships. The use of a Structural Equation Modeling technique in this paper, therefore differs from the approach in many of the studies in RDM. Also, this study employs a two-sided perspective in assessing the relationship' effect in RDM. This approach represents an improvement on the traditional social management perspective.

\section{Results and Discussion}

The assessment of data was done to check for internal consistency, reliability, convergent and discriminant validity to check the strength of the measuring 
items and how they are holding together. The minimum criteria have all been met for various loadings, average variance of various extracted (AVE). The average variance extracted (AVE) for each of the factors is calculated manually for all the constructs using the formula suggested by [33]. The result ranged from 0.504 to 0.698 . Since the AVE value of $\geq 0.5$ satisfies the condition for convergent validity this is a good fit. Apart from funders, Cronbach $\alpha$ were all above 0.7 and that of funders at 0.69 . The composite reliability ranges from 0.774 to 0.898 . This was consistent with the study in [34]. Using the PLS-SEM analysis of study constructs, the direct relationship between stakeholders was assessed according to a method described by [35] as shown in Figure 2.

The result shows that funders positively impact researchers with a path coefficient of 0.092. It also demonstrates that funders have a positive impact on librarians. Funders requirement for accessibility of research data management plan as a prerequisite condition for the ability to access fund have a positive effect on the work of Librarian. This finding therefore confirms the results in American Library [36] that funders have a significant impact on the work of librarians.

Government influence on Librarians was not significant $(\mathrm{p}=0.003)$. This means that hypothesis 3 ("government affects librarian positively") was rejected as the study results did not confirm it. However, this does not mean that government does not have any influence on librarians. It could mean that its effect is an indirect one, given that government interventions to librarians are through institutions, which was found to be the main hindrance to RDMP. Librarians need to update their knowledge to remain relevant to enable them respond positively to enhanced opportunities and influence directions [37]. When government

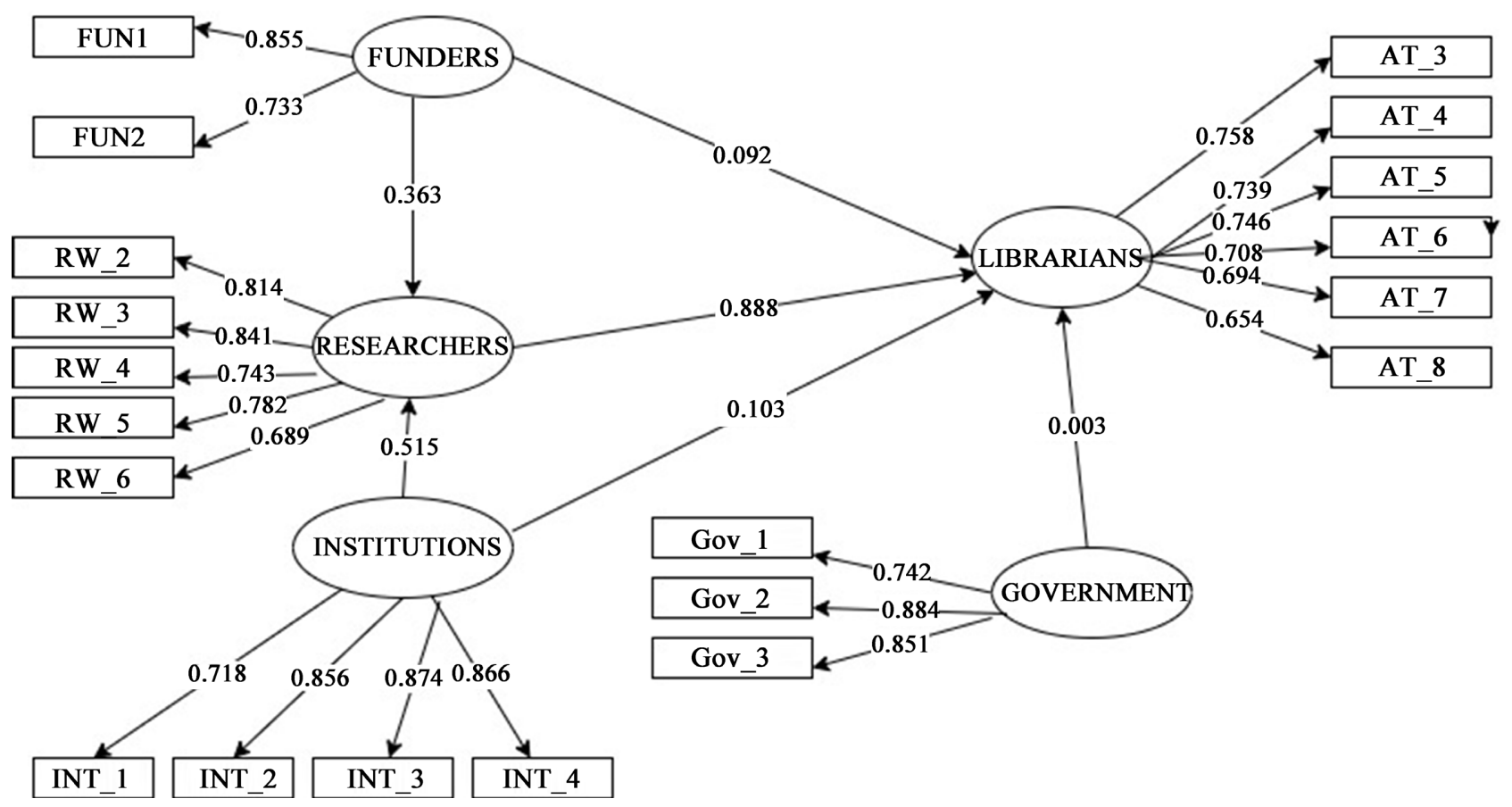

Figure 2. Hypothesis testing (PLS-SEM path model showing relationships between study variables; reproduced) [42]. 
supports, librarians show willingness in their responsibility and learn new skills in this continuous ever-changing environment, and proved useful in new ways.

Furthermore, Institutions were found to have positive effects on the Librarian with a p-value 0.103 . The low p-value of institutions on librarians, however shows the low correlation between librarians and institutions which could improve with demands for Institution's involvement in RDM. This result is clear evidence that the Institution's role can increase librarians' output in research data. Regular training to upgrade librarians' skills and knowledge will go a long way to produce much more positive result as this will boost the confidence. This training proves essential to mitigate the challenges faced by librarians. Many studies conducted point to the fact that there is a need for training [38]. As a very important aspect of successful RDM services to mitigate the challenges of librarians. Also, Infrastructure provision is deemed key to the success of RDM [10].

Institutions have positive impact on the work of researchers. The Institution where the researcher works is responsible for policy implementation. It is also responsible for provision of infrastructure and training to researchers. All these contribute to the level of significance reported in this study. The empirical tests in [39], and [40] also confirms that institutions positively affect researchers' work in fulfilling the need for better research data management policy. This impact is seen in the job satisfaction of the Librarian [41]. The Institution performs a leadership role as well; the leadership style exhibited, therefore, influences positively the job satisfaction of the researcher, which in turn translates to greater efficiency and output of researchers. The institutions positively impact the work of librarians, which intend to increase the work of researchers. In addition, Funder's influence researchers' work ( $p=0.363)$.

The findings revealed that the relationships among different stakeholders are significantly positive, and that institutions mediate the positive effect of Librarian on researchers' work. The effect of government on librarians is not significant. This later finding may be largely due to the poor attitudes of government towards the librarians, however there could be a positive mediating effect rather than direct. Computer literacy effect on librarians is not significant this is because the RDM required a technical skill that librarian are lacking Hence, it is concluded that there is a positive impact of the research variable under consideration (librarians, researchers, institutions and government) and as such stakeholder's relationship affect the research data management as in [43]. This means that when various stakeholders play their roles and responsibility, it motivates one another and causes the other party to be more efficient and effective in managing research data management resulting in quality research [44]. Concerning the librarians, the more the support, the more the output. Librarians are well positioned to lead the RDM agenda and therefore should take a leading role.

\section{Conclusion}

This paper sought to address a set of research questions that seek to discover the 
effect of research variables in research data management: researcher's work, librarians, funders, government and institutions with a focus on librarians' roles towards research data management. This study was grounded on stakeholders' theory. The three variables, namely funders, government, institutions, impact positively on the work of librarians. Besides that, the funders also significantly affect the outcome of researchers in the research data management. The results show that four (4) have a significant positive impact. This means that when various stakeholders and patrons play their roles and responsibility, it motivates the librarians and causes them to be more efficient and effective in their delivery in managing research data management. The more the support, the more the output of librarians. The study found that the librarian's contribution to research data management is impactful and affects the work of researchers positively. Hence, it is concluded that there is a positive impact of the research variable under consideration (librarians, researchers, institutions and government and as such stakeholders affect the research data management). This is consistent with the study by [26], who found a positive correlation among project management stakeholders. In [45], it was found that Corporate Stakeholders such as Institution can influence the performance directly through other internal staff or indirectly through other external stakeholders such as government and funders. Based on this finding, the authors concluded that librarians in China can bring a paradigm shift in the management of data, however, we recommend that librarians need to be certified by government and as such can have a direct relationship with government. Government should take more interest in librarians and regulates their activities. Librarians should take a leading role in RDM and be trained in the required skills for RDM. There should be openness of information, this, we hope, will improve the success story of researchers' work.

\section{Acknowledgements}

This work is sponsored by project of National Social Science Foundation of China, "research on scientific data fusion model design and system construction" (21BTQ080).

\section{Conflicts of Interest}

The authors declare no conflicts of interest.

\section{References}

[1] Semeler, A.R., Pinto, A.L. and Rozados, H.B.F. (2019) Data Science in Data Librarianship: Core Competencies of a Data Librarian. Journal of Librarianship and Information Science, 51, 771-780. https://doi.org/10.1177/0961000617742465

[2] Schmidt, B., et al. (2016) Time to Adopt: Librarians' New Skills and Competency Profiles. 20th International Conference on Electronic Publishing, Göttingen, 7-9 June 2016, 1-8.

[3] Liu, G., Zotoo, I.K. and Su, W. (2020) Research Data Management Policies in USA, UK and Australia Universities: An Online Survey. Malaysian Journal of Library In- 
formation Science, 25, 21-42.

[4] Huang, Y.S., Cox, A.M. and Sbaffi, L. (2021) Research Data Management Policy and Practice in Chinese University Libraries. Journal of the Association for Information Science and Technology, 72, 493-506. https://doi.org/10.1002/asi.24413

[5] Tenopir, C., et al. (2017) Research Data Services in European Academic Research Libraries. LIBER Quarterly. The Journal of the Association of European Research Libraries, 27, 23-44. https://doi.org/10.18352/lq.10180

[6] Cox, A.M., et al. (2019) Maturing Research Data Services and the Transformation of Academic Libraries. Journal of Documentation, 75, 1432-1462.

https://doi.org/10.1108/JD-12-2018-0211

[7] Whitehead, M. and Bourne-Tyson, D. (2016) Multi-Stakeholder Engagement in Research Data Management. International Association of University Libraries.

[8] Chen, X.J. and Wu, M. (2017) Survey on the Needs for Chemistry Research Data Management and Sharing. The Journal of Academic Librarianship, 43, 346-353.

[9] Hall, N., et al. (2013) Model Language for Research Data Management Policies. ASERL \& SURA, Atlanta. https://libraopen.lib.virginia.edu/public view/s1784k74p

[10] Darch, P.T., et al. (2020) Do the Stars Align: Stakeholders and Strategies in Libraries' Curation of an Astronomy Dataset. Journal of the Association for Information Science and Technology, 72, 239-252. https://doi.org/10.1002/asi.24392

[11] Vilar, P. and Zabukovec, V. (2019) Research Data Management and Research Data Literacy in Slovenian Science. Journal of Documentation, 75, 24-43. https://doi.org/10.1108/JD-03-2018-0042

[12] Verbaan, E. and Cox, A.M. (2014) Occupational Sub-Cultures, Jurisdictional Struggle and Third Space: Theorising Professional Service Responses to Research Data Management. The Journal of Academic Librarianship, 40, 211-219.

[13] Whyte, A. (2014) A Pathway to Sustainable Research Data Services: From Scoping to Sustainability. In: Pryor, G., Jones, S. and Whyte, A., Eds., Delivering Research Data Management Services: Fundamentals of Good Practice, Facet, London, 59-88. https://doi.org/10.29085/9781783300242.005

[14] Jolak, R., et al. (2018) Does Distance Still Matter? Revisiting Collaborative Distributed Software Design. IEEE Software, 35, 40-47. https://doi.org/10.1109/MS.2018.290100920

[15] Alvaro, P., et al. (2011) Consistency Analysis in Bloom: A CALM and Collected Approach. 5th Biennial Conference on Innovative Data Systems Research, Asilomar, 9-12 January 2011, 249-260.

[16] Corrall, S., Kennan, M.A. and Afzal, W. (2013) Bibliometrics and Research Data Management Services: Emerging Trends in Library Support for Research. Library Trends, 61, 636-674. https://doi.org/10.1353/lib.2013.0005

[17] Lyon, L. and Pink, C. (2012) University of Bath Roadmap for EPSRC: Compliance with Research Data Management Expectations.

[18] Cox, A.M. and Pinfield, S. (2014) Research Data Management and Libraries: Current Activities and Future Priorities. Journal of Librarianship and Information Science, 46, 299-316. https://doi.org/10.1177/0961000613492542

[19] Zotoo, I.K., Lu, Z. and Liu, G. (2021) Big Data Management Capabilities and Librarians' Innovative Performance: The Role of Value Perception Using the Theory of Knowledge-Based Dynamic Capability. The Journal of Academic Librarianship, 47, Article ID: 102272.

[20] Faniel, I.M. and Connaway, L.S. (2018) Librarians' Perspectives on the Factors In- 
fluencing Research Data Management Programs. College \& Research Libraries, 79, 100-119.

[21] Auckland, M. (2012) Re-Skilling for Research: An Investigation into the Role and Skills of Subject and Liaison Librarians Required to Effectively Support the Evolving Information Needs of Researchers. Research Libraries UK, London.

[22] Malthouse, E.C., et al. (2019) Beyond Reciprocal: The Role of Platforms in Diffusing Data Value across Multiple Stakeholders. Journal of Service Management, 30, 507-518. https://doi.org/10.1108/JOSM-12-2018-0381

[23] Frederick, A. and Run, Y. (2019) The Role of Academic Libraries in Research Data Management: A Case in Ghanaian University Libraries. Open Access Library Journal, 6, 1-16.

[24] Freeman, R.E. (1984) Strategic Management: A Stakeholder Approach. Pitman, Boston.

[25] Sarkis, J., Zhu, Q.H. and Lai, K.H. (2011) An Organizational Theoretic Review of Green Supply Chain Management Literature. International Journal of Production Economics, 130, 1-15. https://doi.org/10.1016/j.ijpe.2010.11.010

[26] Wang, X.J. and Huang, J. (2006) The Relationships between Key Stakeholders' Project Performance and Project Success: Perceptions of Chinese Construction Supervising Engineers. International Journal of Project Management, 24, 253-260. https://doi.org/10.1016/j.ijproman.2005.11.006

[27] Duncan, W. (2005) Project Management Institute. A Guide to the Project Management Body of Knowledge. Automated Graphic Systems, Charlotte, NC.

[28] Angus, G.Y., Flett, D. and Bowers, J.A. (2005) Developing a Value-Centred Proposal for Assessing Project Success. International Journal of Project Management, 23, 428-436. https://doi.org/10.1016/j.ijproman.2005.01.008

[29] Rowley, T.J. (1997) Moving beyond Dyadic Ties: A Network Theory of Stakeholder Influences. Academy of Management Review, 22, 887-910. https://doi.org/10.5465/amr.1997.9711022107

[30] Zotoo, I.K. (2021) Figure 2, in Research 2021, C. Framework, Editor.

[31] Peritz, B.C. (1980) The Methods of Library Science Research: Some Results from a Bibliometric Survey. Library Research, 2, 251-268.

[32] Ullah, A. and Ameen, K. (2018) Account of Methodologies and Methods Applied in LIS Research: A Systematic Review. Library \& Information Science Research, 40, 53-60. https://doi.org/10.1016/j.lisr.2018.03.002

[33] Hair Jr., J.F., Anderson, R.E., Tatham, R.L. and Black, W.C. (1995) Multivariate Data Analysis with Readings. 7th Edition, Prentice Hall International Editions, Englewood Cliffs, NJ.

[34] Hair, J.F., et al. (2016) A Primer on Partial Least Squares Structural Equation Modeling (PLS-SEM). Sage Publications, Thousand Oaks.

[35] Carrión, G.C., Nitzl, C. and Roldán, J.L. (2017) Mediation Analyses in Partial Least Squares Structural Equation Modeling: Guidelines and Empirical Examples. In: Latan, H. and Noonan, R., Eds., Partial Least Squares Path Modeling, Springer, Cham, 173-195. https://doi.org/10.1007/978-3-319-64069-3 8

[36] Arnott, J.C., et al. (2020) Sponsoring Actionable Science: What Public Science Funders Can Do to Advance Sustainability and the Social Contract for Science. Current Opinion in Environmental Sustainability, 42, 38-44. https://doi.org/10.1016/j.cosust.2020.01.006

[37] Das, T. (2020) Academic Library Collaborations to Strengthen Open Government 
Data and Expand Librarianship. In: Open Government. Concepts, Methodologies, Tools, and Applications, IGI Global, Hershey, 1187-1206.

[38] Newton, M.P., Miller, C.C. and Bracke, M.S. (2010) Librarian Roles in Institutional Repository Data Set Collecting: Outcomes of a Research Library Task Force. Collection Management, 36, 53-67. https://doi.org/10.1080/01462679.2011.530546

[39] Moher, D., et al. (2020) The Hong Kong Principles for Assessing Researchers: Fostering Research Integrity. PLoS Biology, 18, e3000737.

https://doi.org/10.1371/journal.pbio.3000737

[40] Oldroyd, R. (1995) Staff Development and Appraisal in an "Old" University Library. Librarian Career Development, 3, 13-16. https://doi.org/10.1108/09680819510083435

[41] Nwaigwe, U. (2015) The Influence of Head Librarians' Leadership Styles on Job Satisfaction of Librarians' in Tertiary Institution Libraries in Imo State, Nigeria. Open Access Library Journal, 2, 1-9.

[42] Ringle, C.M., Wende, S. and Becker, J.M. (2015) SmartPLS 3. Boenningstedt: SmartPLS GmbH. http://www.smartpls.com

[43] Kim, J.H. (2020) Academic Library's Leadership and Stakeholder Involvement in Research Data Services. Proceedings of the Association for Information Science Technology, 57, e304. https://doi.org/10.1002/pra2.304

[44] Zotoo, I.K. and Liu, G. (2019) Research Data Management (RDM) Strategy for Academic Libraries in Ghana: Setting a National Development Agenda. Open Access Library Journal, 6, 1-24. https://doi.org/10.4236/oalib.1105383

[45] Li, G., Lim, M.K. and Wang, Z.H. (2020) Stakeholders, Green Manufacturing, and Practice Performance: Empirical Evidence from Chinese Fashion Businesses. Annals of Operations Research, 290, 961-982. https://doi.org/10.1007/s10479-019-03157-7 